\title{
Processos Psicossociais da Aquisição de uma Deficiência*
}

\author{
Joelma Cristina Santos ${ }^{1}$ \\ Maria Nivalda de Carvalho-Freitas ${ }^{1}$ \\ ${ }^{1}$ Universidade Federal de São João del-Rei, MG, Brasil. \\ ${ }^{1}$ Universidade Federal de São João del-Rei, MG, Brasil.
}

Resumo: A aquisição de uma deficiência pode ter extenso impacto na vida de uma pessoa, pois ocorre, muitas vezes, sob condições traumáticas e obriga tanto a ressignificações subjetivas quanto a adaptações práticas no cotidiano. O principal objetivo do trabalho aqui descrito consistiu em compreender aspectos psicossociais do processo de aquisição de uma deficiência, considerando diversos fatores que podem interferir nestas experiências. Para a realização da pesquisa, foram entrevistadas, de forma semiestruturada, 13 pessoas que adquiriram uma deficiência física, auditiva ou visual na idade adulta, sendo os relatos analisados pelo método de análise de conteúdo. Ao se discutir as falas dos pesquisados, são traçadas algumas semelhanças e distinções entre as experiências dos participantes, buscando também tecer considerações com base na literatura acadêmico-científica sobre o tema. Observou-se que os processos psicossociais de aquisição da deficiência foram permeados tanto por sentimentos negativos, relacionados à angústia e à depressão, bem como por reações mais harmônicas e de valorização da vida, em que se relativiza a perda do membro ou da capacidade sensorial. Representando um momento marcante na vida de quem a adquire, a deficiência pode levar à aprendizagem e ao amadurecimento, à medida que o tempo após a aquisição aumenta. Entende-se que os estudos acerca da deficiência, em especial a adquirida, devem ser ampliados e aprofundados, tendo em vista que o campo de estudos sobre esta temática ainda precisa de mais contribuições a respeito.

Palavras-chave: Deficiência adquirida, Subjetividade, Diversidade.

\section{Psychosocial Processes of Acquiring a Disability}

Abstract: Becoming disabled may cause a considerable impact in someone's life, because, in most of the cases, it happens under traumatic conditions and it results in subjective resignification and practical adaptations. The main objective of this study is to understand the psychosocial aspects involved in becoming disabled, considering several factors which may interfere these experiences. For this research, 13 people who got a physical disability, a hearing or visual impairment in adulthood were interviewed in a semi-structured way and the results were evaluated using the content analysis method of Bardin (2011). When the speeches of the interviewed people are evaluated, some comparisons and distinctions among experiences of the participants are made for establishing relations with academic-scientific literature on this theme. It was noticed that the psychosocial processes involved in becoming disabled were permeated by negative feelings related to anguish and depression, as well as more harmonic reactions and valorization of life, in which the loss of a member or of a sensorial capability is relativized. As a defining moment in the lives of those who acquired it, the disability may result in learning and maturating over the years after the event. It is recommended that the studies concerning disability, especially the acquired ones, get broadened and deepened because there is a need for more contributions about this subject.

Keywords: Acquired disability, Subjectivity, Diversity.

*Agradecimentos: à Coordenação de Aperfeiçoamento de Pessoal de Nível Superior (Capes) e ao Conselho Nacional de Desenvolvimento Científico e Tecnológico (CNPq). 


\title{
Procesos Psicosociales de la Adquisición de una Discapacidad
}

\begin{abstract}
Resumen: La adquisición de una discapacidad puede tener un amplio impacto en la vida de una persona, pues ocurre, muchas veces, bajo condiciones traumáticas y requiere tanto la reinterpretación subjetiva como las adaptaciones prácticas en la vida cotidiana. El principal objetivo del trabajo que se describe aquí fue entender los aspectos psicosociales del proceso de adquisición de una discapacidad, teniendo en cuenta diversos factores que pueden interferir en estas experiencias. Para la investigación, fueron entrevistadas de manera semiestructurada, 13 personas que adquirieron una discapacidad física, auditiva o visual en la edad adulta, siendo los relatos analizados por el método de análisis de contenido. En la discusión de los relatos de los entrevistados, son trazadas algunas similitudes y diferencias entre las experiencias de los participantes, buscando también tejer consideraciones con base en la literatura académica y científica sobre el tema. Se observó que los procesos psicosociales de adquisición de la discapacidad fueron permeados tanto por sentimientos negativos relacionados con la angustia y la depresión, así como por las reacciones más armónicas y de valorización de la vida, en que se relativiza la pérdida de un miembro o la capacidad sensorial. Representando un momento decisivo en la vida de quién la adquiere, la discapacidad puede llevar al aprendizaje y al crecimiento, a medida que el tiempo después de la adquisición aumenta. Se entiende que los estudios acerca de la discapacidad, en especial la adquirida, deben ser ampliados y profundizados, teniendo en cuenta que el campo de los estudios sobre este tema aún necesita más contribuciones al respecto.
\end{abstract}

Palabras clave: Discapacidad adquirida, Subjetividad, Diversidad.

\section{Introdução}

A Organização Mundial de Saúde (OMS) (2011) estima que, no mundo, mais de um bilhão de pessoas tenha algum tipo de deficiência. No Brasil, 23,9\% da população ou aproximadamente 45,6 milhões de pessoas têm deficiência, de acordo com o censo mais recente realizado em 2010 (Instituto Brasileiro de Geografia e Estatística [IBGE], 2012). As deficiências podem ser de natureza física, mental, intelectual ou sensorial (auditiva ou visual), podendo ainda ser distinguidas em função de suas causas e classificadas em hereditárias, congênitas ou adquiridas. Esta diferenciação é importante, considerando-se que cada deficiência tem um impacto psicossocial único (Alves, 2012), a partir da interação com os demais aspectos que compõem a subjetividade de cada pessoa e que estão articulados ao contexto histórico, político, social, cultural e econômico em que ela está inserida. As deficiências hereditárias são transmitidas pelos pais (com manifestação precoce ou tardia) e têm causas genéticas, ocorrendo independentemente da atenção e da assistência à saúde durante a gestação (Souza \& Carneiro, 2007). As deficiên- cias congênitas são aquelas geradas com a pessoa e podem, em certos casos, ser impedidas ou ter sua manifestação amenizada (Souza \& Carneiro, 2007), como as decorrentes de falhas no serviço de atenção primária à saúde (acompanhamento pré-natal inexistente ou incompleto), consequências de doenças maternas (como rubéola, sarampo e toxoplasmose) ou devido ao uso de determinados medicamentos, álcool e/ou drogas durante a gestação, por exemplo. Já as deficiências adquiridas consistem, geralmente, em sequelas de doenças (como diabetes, glaucoma e caxumba), consequências de acidentes de trânsito, de trabalho ou de ferimentos causados por armas de fogo e armas brancas. Informações acerca das causas das deficiências não são comuns em pesquisas de grande abrangência, como os censos nacionais, mas estudo de base populacional, feito por Castro et al. (2008), observou que as principais causas de deficiências são doenças, fatores ambientais, acidentes domésticos, de trabalho e de trânsito.

Brito (2009) destaca que o diagnóstico de uma doença crônica ou a aquisição repentina de uma deficiência causa impactos que interferem em todos os aspectos da vida, tendo em vista que a nova condição 
pode exigir mudanças no estilo de vida, na rotina, nas ocupações e na maneira de lidar consigo mesmo. Tais circunstâncias podem representar grandes desafios e contrastam com as condições vividas por pessoas que nascem ou aprendem a conviver com uma deficiência desde muito novas, distinção que justifica a abordagem desta pesquisa. Conforme Resende e Neri (2009), quando a aquisição da deficiência ocorre mais cedo na vida, as pessoas tendem a apresentar melhor aceitação da deficiência, possivelmente porque os mais jovens costumam ser mais flexíveis em suas atitudes em relação à vida e mais abertos a novas formas de realização de atividades.

Goffman (1982) considera que existem diferenças entre o indivíduo que possui um estigma congênito (como a deficiência), e é socializado nesta condição, e o indivíduo que se torna estigmatizado numa idade mais avançada, uma vez que ele viu e ouviu muitas coisas a respeito de pessoas com estigmas antes de ele próprio ser obrigado a se perceber como "deficiente". Para Stone-Romero, Stone e Lukaszewski (2006), pessoas que adquirem uma deficiência relativamente tarde na vida reagem de forma mais negativa e sofrem mais golpes em seu autoconceito do que pessoas que a adquirem relativamente mais cedo, já que estas não sentiriam tanto a perda da habilidade ou da atividade estimada. Barnes, Mercer e Shakespeare (2005) argumentam que pessoas com deficiência são socializadas no tradicional papel e identidade de "deficiente", de modo a se ajustar à sua própria "tragédia pessoal", sendo que a estigmatização e as expectativas sociais sobre como a pessoa deve se comportar ou o que ela é capaz de fazer exercem influência independentemente da deficiência em si.

Como assinala Patrocínio (2010), a deficiência pode gerar vivências de exclusão, sendo considerada uma condição indesejada, que traz desdobramentos nos contextos sociais de lazer, educação, trabalho, além de ter reflexos na subjetividade, em aspectos da afetividade e da sexualidade, por exemplo. Para Aguiar e Severino (2010), a complexa interação entre preconceitos, estigmas e fatores socioeconômicos e jurídicos é que faz com que a aquisição de uma deficiência na adolescência e na idade adulta tenha conotação negativa na vida de grande parte das pessoas.

Oliveira (2000) assinala que a aquisição de uma deficiência física pode-se constituir num marco importante e determinante na história pessoal de um indivíduo, sendo que a forma como cada pessoa lida com a aquisição é diferente, pois depende da sua trajetória de vida, sua personalidade, seus recursos, apoios sociais e preconceitos prévios acerca da deficiência física em geral. Para Murta e Guimarães (2007), considera-se que seja mais fácil para a pessoa com deficiência física desenvolver comportamentos adaptados desde criança do que para o adulto substituir seus comportamentos já estabelecidos por outros equivalentes, sob o impacto da lesão. Matsuo (1999) observou que algumas pessoas amputadas, devido a acidentes de trabalho, levavam uma vida considerada "normal" (apesar de alguns conflitos no processo de ajustamento) e que a discriminação e o sentimento de perda não predominavam na orientação das ações.

Especificamente sobre a lesão medular - um dos fatores que podem levar à deficiência física adquirida - Fechio, Pacheco, Kaihami e Alves (2009) assinalam que, ao iniciar o processo de reabilitação, muitos ficam restritos à própria casa, queixando-se da situação de dependência e desejando que ocorra um retorno às condições de vida anteriores. Conforme Murta e Guimarães (2007), os fatores ambientais e psicossociais têm impacto maior do que as variáveis físicas da lesão medular, sendo que o dano físico não é em si um problema se a pessoa estiver em um ambiente físico e social estruturado e possuir recursos de enfrentamento suficientes. Além disso, não só a deficiência física adquirida, mas demais consequências da lesão medular (úlceras por pressão, problemas vesico-urinários, incontinência intestinal, entre outras) e novas formas de locomoção e de vivência da sexualidade, por exemplo, ocasionam mudanças significativas que demandam adaptações que determinam um novo modo de vida. Schoeller, Bitencourt, Leopardi, Pires e Zanini (2012) observaram que os participantes do estudo, desenvolvido pelos autores, dividiam sua vida entre antes, durante e depois da lesão medular, relembrando e "revivendo", diversas vezes, o evento que causou a lesão, a fim de compreender melhor a nova condição. Além disso, o tempo decorrido após a lesão colaborou para a adaptação e para um maior conhecimento acerca das consequências da lesão medular, entretanto, este tempo varia de pessoa pra pessoa e depende, entre outros fatores, da idade, da formação prévia, do suporte familiar e das causas da lesão (Schoeller et al., 2012).

Ao analisar as implicações da surdez adquirida em adultos, nas vidas familiar, social e laboral, 
Francelin, Motti e Morita (2010) observaram que as situações de trabalho se mostraram como a área de adaptação mais difícil para o adulto que adquiria a deficiência, uma vez que impactava na segurança social e econômica dele. Como consequências psicossociais da aquisição da deficiência auditiva, as autoras identificaram sentimentos de autodiscriminação e discriminação familiar e social, além de alterações nos relacionamentos, como vivência de situações de estresse e desagregação familiar. Martins (2009), em pesquisa, observou que a deficiência visual adquirida tende a ser percebida como uma catástrofe individual em que os significados da vida e da cegueira se entrelaçam, ao passo que para pessoas que nascem cegas, não existe a experiência de perda ou de ruptura nem de mudança imperativa nas formas de viver o cotidiano. Assim, segundo o autor, pessoas que nascem com deficiência visual têm conhecimento sobre o que as diferencia de quem enxerga, com base na comparação com os outros e na percepção das facilidades que o sentido da visão possibilita para a apreensão de elementos da realidade e a execução de determinadas tarefas, considerando-se a forma predominante de organização social. Para Martins (2009), portanto, pessoas que nascem cegas costumam acolher a deficiência visual sem notório dramatismo e a partir de um maior ajustamento subjetivo em articulação às demais capacidades pessoais que coexistem com a cegueira.

Os estudos citados acima, com foco na deficiência adquirida, ainda são escassos no conjunto das pesquisas relacionadas à deficiência, tendo em vista que a maior parte dos trabalhos tende a considerar, indistintamente, pessoas com deficiências diversas, sem diferenciação entre tipos ou causas. Tal situação denota uma lacuna no campo do conhecimento em virtude da carência de investigações específicas sobre as implicações da deficiência adquirida, especialmente sob perspectivas críticas e psicossociais, indo além dos pontos de vista patologizantes e individualizantes. Assim, este estudo pretende identificar possíveis aspectos psicossociais que ocorrem no processo de aquisição de uma deficiência, quer seja física, auditiva ou visual adquiridas, buscando contribuir para a ampliação do campo teórico pertinente e provocar a reflexão acerca das vivências das pessoas com deficiência adquirida. Além disso, inserem-se tais questões no contexto das experiências de discriminação e preconceito e da necessidade de se desconstruir as barreiras sociais que impedem a plena inserção das pessoas com deficiência.

\section{Método}

Partindo de uma perspectiva qualitativa, os dados foram obtidos por meio de entrevistas semiestruturadas com 13 pessoas com deficiência adquirida na idade adulta. $\mathrm{O}$ acesso e convite aos participantes foi feito por meio de contato com o Serviço Municipal de Fisioterapia da Secretaria Municipal de Saúde de São João del-Rei - que dá suporte ao Programa de Órtese e Prótese do Governo de Minas Gerais, prestando atendimento a pessoas com deficiência - e com a Associação de Surdos de São João del-Rei. Também foi feito contato com empresas de São João del-Rei, MG, que pudessem ter pessoas com deficiência adquirida no seu quadro funcional, de modo a convidar estes funcionários para participação. Outra forma de acesso ocorreu por meio do banco de dados do Núcleo de Pesquisa em Acessibilidade, Diversidade e Trabalho (NACE), da Universidade Federal de São João del-Rei (UFSJ), contatando participantes de pesquisas, já desenvolvidas ou em desenvolvimento, além de pessoas com deficiência adquirida indicadas pelos próprios participantes ou por outros profissionais, no processo conhecido como "bola de neve".

$\mathrm{O}$ roteiro de entrevista previamente elaborado buscou coletar, a princípio, algumas informações objetivas acerca dos participantes, tais como dados sociodemográficos, formação escolar/acadêmica e trajetória profissional, para, então, abordar questões que se referiam à forma como a pessoa adquiriu a deficiência (época, causas e circunstâncias de vida) e aos impactos desta aquisição nas áreas pessoal e profissional. Embora investigasse pontos específicos, o roteiro permitia que os entrevistados falassem livremente sobre temas relacionados às questões de pesquisa. Todas as entrevistas foram gravadas e, posteriormente, transcritas, de modo a possibilitar uma análise mais detida das falas dos pesquisados. As entrevistas foram analisadas pelo método de análise de conteúdo que, conforme Bardin (2011), consiste num conjunto de instrumentos, de caráter metodológico, que pode ser aplicado a variados tipos de discursos. A análise de conteúdo considera a parte comum presente nos dados, passando por três grandes fases: (1) pré-análise, (2) exploração do material e (3) tratamento dos resultados, inferência e interpretação. 
Foram entrevistados oito homens e cinco mulheres que adquiriram a deficiência entre os 22 e 52 anos de idade (média de 34,9 anos). Na época da coleta de dados, a idade dos entrevistados variava entre 27 e 59 anos (média de 45,1 anos) e o tempo de convívio com a deficiência variou de um a 26 anos (média de 10,2 anos). Das 13 pessoas entrevistadas, cinco adquiriram deficiência devido a acidentes de trabalho, três por causa de outros tipos de acidentes (sendo dois relacionados a veículos), três em consequência de doenças, uma devido à sequela de cirurgia e uma por causa desconhecida (perda gradativa da audição sem motivo identificado). Em relação ao tipo de deficiência, nove pesquisados possuíam deficiência física, três tinham deficiência auditiva e um tinha deficiência visual. A maior parte dos entrevistados (seis participantes) tinha Ensino Médio completo quando adquiriu a deficiência, enquanto três tinham Ensino Fundamental incompleto, um tinha Ensino Fundamental completo e três possuíam Ensino Superior completo.

Este estudo foi submetido à Comissão de Ética em Pesquisa Envolvendo Seres Humanos (CEPES) da UFSJ e, conforme orientações da CEPES/UFSJ, os dados colhidos e produzidos pela pesquisa (gravações, anotações e transcrições) serão arquivados por, pelo menos, cinco anos. Os participantes da pesquisa receberam explicações quanto aos objetivos da pesquisa e foram esclarecidos acerca da participação voluntária e da possibilidade de desistência, mesmo após a concessão da entrevista. Todos os entrevistados assinaram o Termo de Consentimento Livre e Esclarecido, concordando com a participação no estudo e tiveram assegurado o sigilo de suas identidades.

\section{Resultados e Discussão}

A fim de contextualizar a discussão e a interpretação dos resultados desta investigação, apresenta-se, a seguir, uma breve caracterização dos participantes do estudo, bem como uma síntese da forma como cada um destes adquiriu a deficiência. Após esta descrição, discutem-se alguns processos subjetivos gerados pela aquisição da deficiência, traçando algumas semelhanças e distinções entre as experiências dos participantes da pesquisa. Os nomes citados são fictícios, a fim de preservar a identidade dos entrevistados.

- Antônio: tem 58 anos, possui Ensino Fundamental incompleto e é artesão. Quando jovem, devido a uma queda, fraturou a rótula, o que ocasionou uma osteomielite (inflamação óssea). Após 29 cirurgias e aos 42 anos, amputou uma das pernas acima do joelho: "Eu tinha pedido até pelo amor de Deus para eles amputarem a minha perna que eu já não estava aguentando mais". Após muitos anos utilizando muletas, Antônio usa, atualmente, uma prótese ortopédica.

- Bernardo: tem 59 anos e possui Ensino Fundamental incompleto. Aos 33 anos, era garçom, quando sofreu um acidente de moto e precisou amputar uma das pernas abaixo do joelho. Poucos meses depois, começou a utilizar prótese ortopédica e, três anos após a amputação, se tornou taxista: “[...] foi justamente por causa da deficiência, caso contrário, não seria taxista”.

- Cláudio: tem 40 anos e, aos 22 anos, sofreu um acidente de trabalho, que o deixou cego e o levou a se aposentar por invalidez. $\mathrm{Na}$ época, Cláudio tinha Ensino Médio completo, mas, posteriormente, cursou Ensino Superior, abriu mão da aposentadoria e, atualmente, é funcionário público.

- Dirce: tem 57 anos e é professora. Aos 37 anos, sofreu um acidente que lesionou a sua medula:

[...] fraturei 21 costelas, ao todo, do lado direito, e uma perfurou o pulmão, e, do lado esquerdo, nove, mas onde não podia fraturar, rompeu, né, fraturou a coluna e rompeu a medula, foi secção completa da torácica, então, fiquei paraplégica desde então.

- Eduardo: tem 51 anos, possui Ensino Superior completo e, atualmente, trabalha como gerente de vendas. Aos 42 anos, quando dirigia o caminhão da empresa em que trabalhava, dormiu ao volante e sofreu um acidente, no qual perdeu o pé direito: “[...]o caminhão foi virando, aquele corrimão de concreto da ponte, [...] eu travei o pé no freio e numa das viradas, um daqueles corrimões entrou na frente do caminhão e empurrou meu pé pra trás".

- Flávio: Tem 50 anos, possui Ensino Fundamental incompleto e é auxiliar de produção numa indústria. Aos 43 anos, sofreu um acidente de trabalho e perdeu o dedo polegar direito numa das máquinas que manejava rotineiramente: 
“[...] eu tava limpando de luvas, o material, uma ferpazinha agarrou na mão e não deu tempo de eu tirar a mão fora".

- Geraldo: tem 53 anos, possui Ensino Fundamental completo e é vendedor. Ele sofreu um acidente de moto e fraturou ossos da perna esquerda (tíbia e fíbula): “[...] o meu acidente, as fraturas não foram moles, que tá dentro da minha perna, tem 14 pinos, tem 12 platinas, ela ficou toda deformada, eu sinto essas dores, fraqueza...". Como sequelas do acidente, Geraldo manca e caminha com dificuldade.

- Henrique: tem 27 anos e trabalhava em atividades rurais, quando sofreu um acidente com um trator (a empresa não fornecia Equipamento de Proteção Individual), tendo que amputar a perna direita abaixo do joelho, aos 22 anos: “[...] eu tava do lado trabalhando assim, a minha calça desfiada, aí puxou minha perna, aí, a máquina levou e quebrou". Na época do acidente, Henrique tinha Ensino Médio completo e, após a aquisição da deficiência, iniciou e concluiu um curso superior. Atualmente, ele trabalha como auxiliar administrativo e faz uso de prótese ortopédica.

- Irene: tem 35 anos, possui Ensino Médio completo e é operadora de caixa. Quando tinha 28 anos, sofreu um acidente vascular cerebral (AVC) que fez com que ela passasse a ter dificuldades de fala e locomoção. Após quatro meses como cadeirante, Irene passou a se locomover com um aparelho acoplado à perna e o apoio de uma muleta, recursos que utiliza até hoje.

- Janaína: tem 39 anos, possui Ensino Médio completo e é cobradora de ônibus. Aos 34 anos, teve otite (inflamação nos ouvidos), que evoluiu para um quadro de perda auditiva nos dois ouvidos. Em consequência, Janaína desenvolveu um quadro de depressão que a deixou afastada do trabalho por seis meses. Atualmente, ela utiliza aparelho auditivo.

- Luís: tem 38 anos, possui Ensino Médio completo e era técnico em manutenção de uma empresa, quando, aos 30 anos de idade, sofreu um acidente numa máquina e perdeu o braço esquerdo na altura do ombro: “[...] eu fui com a mão esquerda, a hora que chegou aqui assim, pegou na luva, puxou de uma vez...”. Após cinco anos sem trabalhar, Luís, atualmente, é comerciante.
- Milena: tem 33 anos e possui Ensino Superior completo. Trabalha como auxiliar administrativa e, há aproximadamente seis anos, teve uma paralisia facial de causa desconhecida. Após três meses com o rosto paralisado e sem êxito nos tratamentos medicamentoso e fisioterápico, ela passou por uma cirurgia e, como sequela, perdeu a audição do ouvido direito.

- Neusa: tem 46 anos e possui Ensino Médio completo. Ela trabalha como auxiliar de serviços gerais e, há aproximadamente quatro anos, percebeu que estava perdendo a audição. Como teve dificuldades em lidar com a aquisição da deficiência, Neusa demorou a procurar assistência médica e havia começado a usar aparelho auditivo, nos dois ouvidos, quatro meses antes da concessão da entrevista para esta pesquisa: "No início não queria aceitar, os outros ficam olhando pra gente, né, uns pensam que a gente não fala".

A maneira como cada pessoa lida com a aquisição de uma deficiência depende de inúmeros fatores subjetivos e objetivos, como características de personalidade, aprendizagens anteriores em relação à deficiência, condições socioeconômicas, apoios sociais, consequências da deficiência no cotidiano, momento profissional vivido, tempo e forma de aquisição da deficiência (Francelin, 2007; Oliveira, 2004). Nesta pesquisa, foi possível identificar alguns aspectos psicossociais que, a despeito das idiossincrasias das histórias de aquisição da deficiência, apareceram em todos os relatos, são eles: (1) relação entre a forma de aquisição da deficiência e o processo de aceitação/ adaptação; (2) visibilidade do estigma e preocupação com a avaliação dos outros; e (3) construção de estratégias para lidar com a deficiência adquirida.

\section{Relação entre a forma de aquisição da deficiência e o processo de aceitação/adaptação}

Observou-se que o fato de a deficiência ocorrer repentinamente, em decorrência de acidentes, ou até de forma esperada, como nos casos de doenças, interferiu no processo de aceitação e adaptação, mas não determinou a velocidade nem quão bem-sucedido se deu o andamento deste processo. Assim, os pesquisados relataram desde momentos difíceis de aceitação da deficiência e de depressão até a busca pela rápida 
adaptação e a atitude de agradecimento pela vida, em detrimento do sofrimento pela perda do membro ou da capacidade sensorial. Neste sentido, mas longe de ser uma regra, percebeu-se que a aquisição inesperada de uma deficiência ocasionou processos mais difíceis de aceitação e adaptação, em comparação aos da aquisição "prevista", o que pode ser percebido pelos relatos abaixo:

[...] minha cabeça não parava, um trilhão de pensamentos, uma carga pesadíssima. [...] no início, assim, igual eu falei, deprimente, não pensei que ia passar por isso tudo que eu já..., eu pensei até numas bobagens, assim, "ah, se eu não voltar a enxergar, acho que eu não quero viver mais" [...] (Cláudio).

Então, um período assim bastante negro, né, bem difícil, que exige muita força de vontade e cabeça, né? Se não tiver cabeça, não vai não, porque, de repente, você ser freada a 300 por hora e parar... o pior não é a perda do movimento, te falo, o pior é a perda da sensibilidade. Porque não só movimentar, porque você não sentir, você perder controle vesical, de esfíncter, você passar a conviver com fralda, com tudo, 24 horas por dia, eu faço esvaziamento vesical com sonda quatro vezes ao dia, de seis em seis horas eu passo, essa é a minha rotina ad aeternum, né? (Dirce).

[...] eu fiquei muito chocado, na hora que eu acordei da cirurgia, não tinha ninguém no quarto, eu já tava até no pós-cirúrgico, eu já imaginava, mais ou menos, o que tava pra acontecer, mas só que a gente nunca quer que acontece aquilo, mas querendo ou não, eu não era bobo, eu sabia, do jeito que a minha perna foi que eu vi, que tava dobrada assim, que dava pra ver que a circulação, ela não passa, que o pé começa a ficar sem circulação, ele começa a ficar uma cor mais escura, começa a inchar, eu já imaginava que boa coisa não vinha, aí no eu acordar, claro, eu chorei muito, tava querendo acordar de um pesadelo, pra mim não era aquilo que tava acontecendo comigo [...] (Henrique).

A aquisição repentina de uma deficiência, como no caso da perda da visão de Cláudio, da paraplegia de Dirce e da amputação de Henrique, gerou perío- dos de grande dificuldade, angústia e incerteza acerca do processo de recuperação. Segundo Martins (2009), o sentimento de angústia e a experiência de ruptura vivencial estão fortemente presentes nos casos de perda rápida, repentina ou inesperada, ao contrário dos casos de perda gradativa da visão, por exemplo. Para o autor, o sofrimento envolvido na deficiência visual que ocorre de forma abrupta decorre da experiência traumática, muitas vezes, tida como tragédia não anunciada. Assim, o impacto da perda da visão pode estar ausente ou ser bastante atenuado nos casos de um processo gradual de cegueira (Martins, 2009). Entretanto, nem sempre se tem a percepção imediata de que a deficiência é definitiva e, neste sentido, abre-se espaço para a fala de Irene, que ficou com parte do corpo paralisada, como sequela de um AVC. No seu caso, após uma evolução na recuperação dos movimentos, o processo estagnou, culminando na constatação de que a deficiência era definitiva, dois anos após o AVC:

Nossa Senhora... é a pior coisa que podia ter acontecido [...]. Eu fiquei encostada dois anos, aí quando foi em 2010, aí não ia poder manter isso, nossa, foi um choque pra mim, porque eu ainda tinha esperança que eu ia andar normal, porque agora eu sei que eu não vou ficar, é triste, mas é a realidade, agora eu tô aceitando, aceitando e não aceitando, porque, pra mim, isso aqui não é normal, porque quem era normal, fazia de tudo, agora ficar... hoje eu faço, assim, de tudo, praticamente, mas eu dependo, não faço do jeito que eu fazia antes, entendeu? (Irene).

A comparação com o que se julga ou não "normal", na perspectiva do senso comum, é muito presente na fala dos entrevistados e se destaca, em especial, no relato de Irene que costuma se analisar e avaliar suas capacidades com base no que era e fazia antes de sofrer o AVC. Por outro lado, a aquisição gradativa de uma deficiência também não é bem assimilada sempre e pode gerar muitos danos indiretos, como no caso de Janaína que, em decorrência da progressiva perda da audição, desenvolveu um quadro de depressão, do qual ela ainda não se recuperou totalmente após quatro anos de aquisição da deficiência:

[...] eu comecei com o meu problema de audição, devido a uma otite que eu tive, aí o tratamento, 
durante seis meses, com antibiótico [...] anti, é, antialérgico, uns seis meses, aí não resolveu [...], comecei a entrar em depressão, aí voltei nele [médico], ele falou assim "então, vamos colocar um tubinho de ventilação", colocou tubinho de ventilação nos dois ouvidos, aí o incômodo melhorou, só que com o passar do tempo, eu fui perdendo a audição do ouvido direito, [...] do ouvido esquerdo eu já escuto mais, aí, com isso... eu tenho depressão até hoje por causa disso, tomo remédio controlado, antidepressivo, remédio pra dormir, pra insônia, não durmo direito se eu não tomar, às vezes, eu tomo e nem durmo [...].

As complicações decorrentes da otite e a aquisição da deficiência auditiva impactaram a vida de Janaína de tal forma que mudaram o seu modo de perceber a realidade e de se relacionar com as pessoas. A baixa autoestima e a baixa autoconfiança, características da depressão, foram alguns dos aspectos relatados, com grande frequência, por pessoas com deficiência auditiva adquirida, conforme pesquisa realizada por Francelin (2007). Tais fatores levam a limitações funcionais e prejuízos nos relacionamentos interpessoais estabelecidos e, como a autora ressalta, a não aceitação da deficiência, mesmo que em graus mais leves, pode acarretar prejuízos à vida da pessoa. Marin e Góes (2006) argumentam que a formação da subjetividade das pessoas com deficiência auditiva depende da forma como as relações sociais são constituídas e significadas, mediante as características da deficiência e as formas pelas quais a deficiência é percebida socialmente, em situações de maior ou menor acolhimento. Neste sentido, destaca-se a especificidade da deficiência auditiva, que influencia diretamente na comunicação e, consequentemente, na interação e na construção/manutenção de relacionamentos. Tendo em vista que boa parte das pessoas sem deficiência tem dificuldades em se comunicar por gestos e sinais, isto as leva, muitas vezes, a evitar o contato interpessoal com pessoas com deficiência auditiva.

\section{Visibilidade do estigma e preocupação com a avaliação dos outros}

Outro aspecto a ser destacado refere-se à visibilidade do estigma - no caso, a deficiência - que, conforme Goffman (1982), envolve estratégias que permitem ou não que uma diferença individual forneça informações de que uma pessoa a possui. Considerando-se que a deficiência auditiva tem certo caráter de invisibilidade, uma vez que, à primeira vista só pode ser percebida pelo uso da prótese auditiva e, posteriormente, pelas dificuldades de comunicação interpessoal, ela pode ser escondida ou disfarçada, o que é feito por muitas pessoas, como Janaína: “[...] eu tenho vergonha de usar o aparelho, mas eu uso, aí tampo com o cabelo assim...". Como sugere Francelin (2007), a preocupação com a aparência pode fazer com que a pessoa com deficiência auditiva evite o uso do aparelho, pois este evidencia o que a pessoa pode querer esconder, por motivos de insegurança ou vergonha, bem como para poder evitar uma possível discriminação. Esta questão, entretanto, não afeta todas as pessoas com deficiência da mesma maneira, tanto que Milena diz: "ah, vergonha, vergonha de você escutar? Aí não sei como que é, mas, eu não tenho, não [vergonha do aparelho], pra mim fez muito bem, foi muito bom". Destaca-se que a adaptação a qualquer deficiência adquirida, exige mudanças, notadamente, no modo como a pessoa se vê e na forma como ela quer ser vista pelas outras pessoas, o que parece ainda não estar bem resolvido para Janaína.

A questão da visibilidade da deficiência adquirida não se faz presente apenas no caso de deficiência auditiva, mas também para pessoas cujas deficiências são quase permanentemente visíveis, como é o caso das pessoas com deficiência física. Para Ferreira e Oliver (2010), a pessoa com deficiência física adquirida, ao circular socialmente, pode se expor a experiências de preconceito e a olhares curiosos sobre a deficiência, o que influencia na construção da identidade de "ser deficiente", como pode ser ilustrado pelo relato de Irene:

Agora, eu tô aprendendo a viver assim, né, porque antes eu tinha vergonha de tudo, agora não tô nem aí, se os outros estão falando ou não, fico, lógico, mas, fazer o quê? [...] E é muito triste porque eu sempre fui normal, aí quando vê os outros me veem na cadeira de rodas, é a pior coisa que tem, você precisa de ver uma vez que a gente veio aqui no Centro, que era final de ano, a gente tinha que comprar presente pros meus sobrinhos, precisa de ver os olhares dos outros, aqueles olhares compridos, era pior pra mim, aí eu começava a chorar, porque os outros sempre te "viu" normal, 
aí te vê na cadeira de rodas, os outros olhando, aí é a pior coisa que tem.

Conforme Martins e Barsaglini (2011), a visibilidade ou invisibilidade da diferença física influenciam os contatos sociais estabelecidos pelo indivíduo e, embora a deficiência ocultada evite a exposição, ela mantém o receio da descoberta. Segundo Goffman (1982), dependendo do meio social em que a pessoa estigmatizada está inserida, ela pode vivenciar dois tipos de situação, nos quais: (1) sua característica distintiva é conhecida ou imediatamente evidente ou (2) seu estigma não é conhecido nem prontamente perceptível. No primeiro caso, o indivíduo é desacreditado porque seu estigma é facilmente percebido, geralmente, de forma visual, e ele manipula a tensão e a incerteza gerada nos contatos sociais, de modo a produzir uma interação espontânea. Estas pessoas tendem a adotar a estratégia do acobertamento, isto é, estão prontas a admitir que têm um estigma, mas podem realizar grandes esforços para que ele não apareça muito.

Conforme Goffman (1982), no segundo caso, a pessoa é desacreditável, pois sua diferença não está imediatamente visível e não se tem dela um conhecimento prévio. Assim, não é a tensão que é manipulada, mas a informação sobre o estigma, ou seja, a decisão de mostrá-lo ou ocultá-lo, e em quais circunstâncias. As pessoas desacreditáveis podem encobrir o estigma, a fim de que ele não seja percebido ou para que esta descoberta demore a acontecer. $\mathrm{O}$ pesquisado Henrique relata, abaixo, a diferença na forma de tratamento das pessoas em relação a ele, caso a deficiência esteja ou não visível:

[...] no começo acabou tendo um pouco de constrangimento por questão visual mesmo, mas isso aí foi só no começo, só que a gente fica meio com medo da reação das pessoas, porque muitas pessoas me "vê" um cara muito novo, reage diferente, porque eles reagem de duas maneiras, igual vou te dar um exemplo: quando eu tô de short, todo mundo me vê de um jeito, tem lugar pra sentar [no ônibus], aí eu vou sentar, eles deixam e tal, eu tô de calça, sou um jovem normal, comum.

Para Goffman (1982), a aprendizagem das estratégias de encobrimento constitui uma fase do processo de socialização da pessoa estigmatizada e quando ela passa a "desaprender" o encobrimento e a revelar o estigma voluntariamente, se aceita e se respeita, ela estaria em uma fase mais madura e bem-ajustada, como pode ser exemplificado pela fala de Dirce:

A preocupação como o outro vai te enxergar. Isso é difícil. Aí, a gente tem que ter muito cuidado porque senão você mesmo se isola, você se fecha num casulo. Então você tem que ter muita coragem pra enfrentar, abrir espaço pro outro chegar, porque, às vezes, o preconceito maior está é na gente e não no outro, né? [...] pensar "nossa, como que o outro tá me vendo?", tem que vencer essa barreira, quem não vence, fica quieto dentro de casa e sofre muito, eu acredito que sofre muito.

A reação pública a um estigma individual impacta os relacionamentos interpessoais e, para Ferreira e Oliver (2010), pessoas com deficiência física adquirida podem vivenciar uma grande diminuição das suas relações, já que é comum o surgimento de empecilhos à participação e à circulação social, o que influencia na quantidade e na qualidade das interações. Martins e Barsaglini (2011) argumentam que a aquisição de uma deficiência física pode representar uma crise imediata na identidade, uma vez que as diferenças que agora se apresentam no corpo provocam uma ruptura com o referencial de identificação já estabelecido. Em pesquisa com pessoas com deficiência física adquirida, os autores observaram que o "estar em público", sem uma parte ou uma função corporal, mostrou-se uma preocupação comum que alterava o ritmo de vida dos participantes do estudo, em virtude da constante possibilidade de exposição, mesmo que indireta, da deficiência. Neste sentido, a reinserção social também foi destacada pelos participantes deste estudo como uma das diferenças entre a deficiência adquirida e a deficiência congênita/hereditária, além de outras comparações, como exemplificado por Dirce:

[...] o medo de enfrentar o público era muito grande, porque uma coisa é você ter uma deficiência de nascença, outra coisa é você adquirir depois. Então, você sua frio, te tira do centro [...] é um trauma muito forte, porque a deficiência adquirida, ela é muito pesada. 
Como ressaltam Othero e Ayres (2012), existem diferenças entre as experiências de pessoas que conviveram desde muito jovens com a deficiência e aquelas que lidaram com uma grande ruptura na vida e que demandou novas modalidades sensório-motoras de apreensão do mundo. Este marco na história de vida origina comparações com os modos de viver antes da aquisição da deficiência:

É horrível, antes não tivesse acontecido isso, mas a gente não pede, né? [...] Eu, sinceramente, dos $100 \%$ que eu era, hoje eu funciono aí $30 \%$, por causa das limitações, eu não jogo uma bola, eu não posso andar mais distância, eu não subo morro, escada [...], a gente fica inseguro, quando eu vou atravessar a rua, por exemplo, eu tenho que ter certeza que eu posso atravessar, porque do contrário, eu fico até com medo, porque o carro não espera você atravessar e é um risco muito grande, eu tenho um medo danado de quebrar essa perna novamente, de machucar [...]. Hoje eu vejo que a gente fica se sentindo diminuído mesmo, infelizmente, eu não tô certo de pensar assim, eu deveria pensar o contrário, mas fazer o quê, é a realidade, né!? (Geraldo).

[...] tem hora que tem aquelas coisas, ah, podia ser diferente, lógico que enxergar é muito melhor, eu sei o quê que é, quê que é enxergar e não enxergar, mas aí, ao mesmo tempo a gente pensa, fazer o quê, né? Não tem muito jeito, né? Não é fácil você concordar com isso, por isso que muita gente vive de mau humor, de mal com a vida, na minha situação, entendeu? Mas, aí, aconteceu... (Cláudio).

\section{Construção de estratégias para lidar com a deficiência adquirida}

Ainda sobre o impacto da aquisição da deficiência, é necessário observar os casos em que esta aquisição é mais bem aceita, em atitudes de valorização da vida que foi preservada elou de apoio na religião, como forma de entendimento e de aceitação do ocorrido. Este tipo de percepção a respeito do acontecimento que ocasionou a deficiência, demonstrado por alguns entrevistados, auxilia no processo inicial de superação das dificuldades e de adaptação à nova realidade. Tal circunstância pode ser compreendida pelas falas de Luís, Bernardo e Eduardo - que amputaram o braço, a perna e o pé, respectivamente, como consequência de acidentes:

[...] eu nunca me abati, não, eu sempre pensei assim que eu, eu, me fala, "ah, você perdeu o braço", eu não perdi o braço, eu ganhei a vida, era pra mim ter morrido, não era pra mim tá vivo de jeito nenhum, entendeu? (Luís).

Eu acho que é um milagre que acontece na vida da gente, que Deus conforta a gente, porque acho que as pessoas ao meu lado sofreram muito mais do que eu, eu não tava nem aí, eu queria era viver, eu acho que, com relação a mim, eu tinha a mesma disposição, a mesma vontade de viver, de trabalhar, não mudou nada (Bernardo).

[...] quando eu percebi o pé amassado e arrebentado, houve até uma consciência de satisfação, aí depois eu até brincava com os amigos, porque foi meio traumático, "não, eu passei a perna em Jesus, eu troquei com Ele o pé pela vida e fiz um 'negoção' com Ele danado". [...] a perda, pelo estado que eu tava, pelo momento que tava, o pé, foi uma graça, um lucro pra mim e eu não dei muita importância, na realidade [...]. Minha família ficou muito chocada, minha mãe e o pessoal todo, filhos, eu não, eu achei que a coisa pra mim tava boa demais (Eduardo).

As falas de Bernardo e Eduardo também são representativas do quanto o impacto da aquisição da deficiência não é exclusivo para quem a adquire, mas constitui-se também como uma "experiência de deficiência" para as pessoas que fazem parte do convívio social da pessoa, como observado nos estudos de Lopes e Leite (2013, 2015). De acordo com Oliveira (2000), na aquisição da deficiência física, a pessoa passa por uma fase aguda e outra de evolução crônica, nas quais se vê entre duas situações opostas: a recuperação ou a morte. A vivência da amputação, exemplificada nos relatos acima, demonstra que o indivíduo recorre a diversas crenças e valores subjetivos, que possibilitam a adaptação às novas realidades física e psicossocial. Conforme Oliveira (2000), a perda, real e imaginária, do 
membro obriga a pessoa a realizar uma nova síntese do espaço próprio, desencadeando elementos subjetivos relacionados aos fragmentos do corpo e, em particular, ao valor do membro perdido. Como fala Matsuo (1999), quando a pessoa nasce com a deficiência física, sua identidade social é construída também sobre a deformidade e a imagem corporal pode não se modificar ao longo da vida. Por outro lado, uma amputação na vida adulta promove a (re) construção da identidade social e exige que se (re) aprenda a (con)viver com a amputação, num processo de mudanças abruptas em todas as relações sociais estabelecidas (Matsuo, 1999). Em consonância, Paiva e Goellner (2008) verificaram que os amputados, participantes do seu estudo, ressignificaram suas vidas a partir do olhar dos outros e também de si mesmos para a parte ausente de suas corporalidades. Este processo de adaptação pode ser vivenciado de diversas maneiras e, não só no caso da amputação, mas em outras formas de apresentação de uma deficiência adquirida, diversos recursos ajudam a aliviar o impacto inicial. Deste modo, como parte do processo de aceitação, observa-se, em muitas pessoas, a convicção de que a deficiência foi predestinada por Deus ou pelo destino:

Parece que eu fui preparado, eu acho que todas as pessoas que vão, eu vejo desta forma, espiritualmente, estão preparadas e Deus é muito sábio, não manda uma amputação pra quem, de repente, não vai dar conta de suportar o "defeito". E a gente tem uma missão, eu acho, de você fazer o normal e fazer o que o outro faz e, de repente, você, "peraí, aquele lá tá faltando um pedaço, e ele faz igual, porque que eu não posso fazer?”. [...] não poderia porque tinha que acontecer, mas eu poderia ter parado e dormido e eu não dormiria em cima da ponte, entre aspas, mas aí eu ia acidentar com outro carro, porque o acidente meu tinha que acontecer (Eduardo).

[...] no dia, fiquei bastante pra baixo, só não chegou a me dar depressão, isso chegou a me dar, não, aí eles conversaram comigo, essa coisa que me aconteceu tinha que acontecer, mas, me acolheram bem, minha família me deu o maior apoio (Flávio).
Como observam Othero e Ayres (2012), a religião (e a ideia de castigo, culpa, transcendência ou aprendizado) e a noção de acidente e/ou fatalidade são explicações comuns para a deficiência, conforme relatos de pesquisa feita, pelos autores, com pessoas com diversos tipos de deficiência, congênita ou adquirida. A história individual, as crenças e concepções pessoais, além das vivências concretas, possibilitam que o indivíduo se adapte à experiência própria de ter uma deficiência, a qual pode ser ressignificada ao longo da vida (Othero \& Ayres, 2012). Além disso, a comparação com outras pessoas que estariam passando por uma situação mais difícil também é um recurso utilizado na aceitação da nova condição física, como relata Dirce, ao ficar paraplégica:

Aí, voltei pra casa e aí que foi a verdadeira adaptação, porque é o enfrentar a vida. Mas foi uma escola no hospital, foi uma escola. Primeiro, até porque você vê outros casos e aí você conviver com isso, você vê que você não tá tão ruim, né? Você não tá tão péssimo assim porque você vê cada situação que você fala "nossa, graças a Deus, tô bem porque minha cabeça foi mantida”, aí dá realmente pra enfrentar.

A comparação com o outro, cuja lesão seria mais grave, ajuda a melhorar a autoestima e a percepção de si mesmo, amenizando as dificuldades inerentes à situação vivenciada. Não cabe aqui avaliar até que ponto a estratégia de se basear na "tragédia do outro" é válida ou não, uma vez que tais processos de aceitação são únicos para cada indivíduo.

Passados os momentos iniciais da aquisição da deficiência, abre-se, então, espaço para o enfrentamento do ocorrido e o processo de adaptação:

[...] a gente se percebe, e fala "não é que eu tô dando conta de viver assim", entendeu!? Aí, fui buscando as melhores maneiras possíveis de me adaptar e fazer o quê? Já tava sentindo que, futuramente, eu poderia ter essa necessidade de viver sem enxergar mesmo. Aí, não é que eu acostumei, que eu gostei, não, mas eu busquei formas de melhorar minhas condições de vida [...]. A adaptação do acidente foi quase que uma obrigação, ou eu adaptava ou me deprimia e ficava deitado na cama o dia inteiro, foi quase que uma necessidade, era uma necessidade, mas, as necessida- 
des, você encara elas ou você se anula, só que eu encarei e fui assim (Cláudio).

[...] tomo banho em qualquer banheiro em pé com uma perna só, então, você vai aprendendo, você vai desenvolvendo, o cérebro da gente começa a acostumar com a falta do espaço, existe a sensação de estar completo, aí no começo você tende a apoiar, aí você cai e no cair, você fala "não, não é pra cair, eu tenho que lembrar que não tenho o pé”. Então, hoje, eu tenho uma vida, posso te dizer, normal (Eduardo).

E eu ando normal, só não jogo bola, o resto, danço, eu não me sinto inválido hora nenhuma, eu, às vezes, fico até chateado quando alguém acha que eu sou incapaz, eu sou capaz (Bernardo).

A família, querendo ou não, sempre fica muito preocupada com a gente, [...] na época eu namorava, não queria nem ver minha namorada nem pintada de ouro, não queria que ela entrasse na sala de cirurgia pelo impacto mesmo que eu tive, eu tava com medo de todas as pessoas terem aquele impacto, aí com o passar do tempo eu vi que não era bem aquilo, eu vi que a coisa poderia ir mudando. [...] antes, eu jogava bola, praticava esportes, corria, então, hoje em dia, eu só não posso correr, porque tem uma prótese especial pra quem corre e ela é muito cara, mas tirando disso, eu faço atividade física normal, caminhada, faço academia, coisas que eu pensava que nunca mais ia voltar a fazer (Henrique).

Pelos relatos acima, pode ser notado o desenvolvimento de trajetórias de vida que permitiram que os entrevistados aprendessem a conviver com a deficiência e com as novas condições de vida. Neste sentido, ressalta-se a fala de Henrique, que atribui a limitação para não correr ao valor financeiro de uma prótese específica e não à ausência do membro inferior, demonstrando parte da complexidade implicada na vivência de uma deficiência. Além disso, podem ser observados casos em que a deficiência possibilitou novos rumos à vida, como ocorreu com Henrique e Cláudio, que saíram das empresas em que se acidentaram e cursaram ensino superior após a aquisição da deficiência, em áreas totalmente distintas das atividades que eram exercidas por eles. Neste sentido, a his- tória de Cláudio é emblemática, pois o seu ingresso no Ensino Superior só aconteceu por causa do incentivo de uma instrutora da instituição para cegos, em que realizava sua reabilitação (aprendizagem de leitura em Braille, uso de bengala, manejo do computador):

Na verdade, eu não quis fazer faculdade... Tipo, aqui, a gente não vê, eu, pelo menos, eu não conhecia casos de pessoas que não enxergavam e fizessem uma faculdade. Mas aí, ela falava, conforme o curso foi passando, mas aí "como é que vou estudar?", "não, tem as pessoas que leem pra você". Eu ainda não tinha muita habilidade com o computador, não, entendeu? "Mas aí, só ler, e matemática, como é que eu faço?”, "não, tem jeito, eu arrumo uma pessoa, pessoas que já trabalharam e tal". E assim que foi, eu fui tomando gosto e tal. Aí, quando eu assustei, eu já tava fazendo o curso, mas assim, te falar que escolhi, eu que quis, não, eu só fui querer depois que eu vi que tinha condições, entendeu? (Cláudio).

A fim de encerrar estas considerações acerca dos processos subjetivos de aquisição de uma deficiência, apresentam-se as falas de Eduardo e Dirce, que atribuem à deficiência um impacto positivo na forma de ver a vida, destacando como a aquisição contribuiu para o próprio amadurecimento pessoal:

[...] antes da amputação, eu imaginava que eu era super-herói, eu fazia tudo, eu não tinha limitação, as coisas aconteceriam só com os outros, nunca comigo, então, eu me permitia um ritmo que era totalmente irracional [...], depois da amputação, eu comecei a falar assim, "peraí, você não é indestrutível, você pode fazer tudo que você tem que fazer, mas com racionalidade", eu aprendi isso. Tô aprendendo até hoje. Então, houve essa mudança muito grande e acho que, na verdade, a amputação é pra mudança ou para você ou para as pessoas que estão do seu lado. [...] eu sou um amputado que, normal, operado, não me mudou, aliás, me mudou interiormente, fez com que eu ficasse melhor, mas não fez com que eu ficasse negativo, não (Eduardo).

A gente, acho que fica mais humana, a gente, o sofrimento ensina muito, né? Então, você passa a enxergar o outro de uma maneira também mais 
cuidada, até prazerosa, você dá valor às mínimas coisas. A gente só dá valor às coisas quando perde, infelizmente [...]. Eu valorizo muito mais as coisas, eu sei reconhecer, eu sei mais ouvir e cobro com mais categoria, eu brinco com eles: "de cadeira, né, gente, tem dó, eu tô falando de cadeira". Então acho que isso muda muito a visão da pessoa, eu acho que isso ajuda muito, eu acho que eu sou uma pessoa melhor do que era (Dirce).

Como relatado por Patrocínio (2010), a deficiência adquirida desponta como um "divisor de águas", que demarca as fronteiras entre um antes e um depois, porém não é possível afirmar que a vida após a deficiência seja pior ou melhor do que a anterior, pois os sentidos atribuídos à nova condição são singulares. A experiência da deficiência adquirida exige a (re)construção de hábitos, valores e atitudes, já consolidados, e as vivências impactantes advindas da aquisição da deficiência possibilitam um novo olhar para a vida que pode passar a ser vista com maior valor (Patrocínio, 2010). O "lado positivo" da deficiência pode ser sintetizado, como visto nos relatos acima, pelo amadurecimento pessoal e pelo aprendizado nas relações humanas, que se manifestam no modo de lidar com o outro e de perceber a si próprio.

\section{Considerações Finais}

Este artigo buscou traçar algumas características singulares da aquisição de uma deficiência, em comparação à deficiência congênita ou hereditária, além de procurar ilustrar os impactos únicos que esta aquisição provoca. A diversidade de experiências revela pontos de vista negativos e positivos, os quais são reflexos da combinação específica dos aspectos que integram a vida de cada um, impossíveis de serem padronizados. Na grande maioria das vezes, quanto maior o tempo decorrido da aquisição, melhor é a análise que a pessoa faz da vida pós-aquisição da deficiência, até mesmo, em função de ela estar mais bem-adaptada aos ambientes e do fato de as pessoas de maior convivência lidarem de forma mais natural com a pessoa com deficiência.

Considerando o pequeno volume de investigações a respeito da deficiência adquirida, espera-se que este trabalho possa contribuir para expandir as discussões sobre os processos psicossociais da aquisição de uma deficiência, bem como enriquecer a lite- ratura acadêmico-científica sobre este tema. Os dados coletados e analisados confirmam a percepção de que a aquisição da deficiência representa um momento marcante na vida, não só de quem a adquire, mas também na vida de quem convive com a pessoa com deficiência adquirida, gerando, em alguns casos, consequências dolorosas, mas, em outros, sendo conduzida de maneira harmônica e levando a aprendizados e ao amadurecimento de todos os envolvidos. Além disso, este trabalho complementa e amplia o quadro temático ao integrar os pontos de vista sobre a forma de aquisição da deficiência, a visibilidade de estigmas, a relativização da deficiência pela comparação com outras pessoas ou situações, a elaboração de novas trajetórias para a vida pós-aquisição da deficiência e a tendência à valorização do aprendizado decorrente da experiência da deficiência adquirida. Ao se articular os relatos e experiências semelhantes em três categorias principais, tal como feito no decorrer deste artigo, espera-se colaborar para o desenvolvimento do conhecimento científico e o escopo teórico acerca da deficiência adquirida e suas peculiaridades, abrindo caminho para que outros estudos possam partir de tais perspectivas e aprofundá-las ou inserir novos olhares a respeito. Destaca-se, ainda, que, neste estudo, houve prevalência de participantes com deficiência física em relação a participantes com deficiências auditiva e visual, a qual é um reflexo da forma de acesso e de recrutamento dos entrevistados. Desta forma, aponta-se a necessidade de que sejam desenvolvidas pesquisas futuras que analisem, de forma mais detalhada, o processo de aquisição de deficiências sensoriais.

A importância de se discutir os aspectos mencionados acerca da deficiência adquirida reside na necessidade de se dar voz às experiências das minorias sociais, de modo a se ampliar a discussão sobre uma diversidade legítima nos mais variados espaços. A inclusão social plena ainda representa um grande desafio para pessoas com e sem deficiência e a busca por acessibilidade e oportunidades igualitárias deve ser constante, de modo a não se naturalizar obstáculos físicos e relacionais. A desconstrução de barreiras arquitetônicas, discriminatórias e de preconceito facilita os contatos interpessoais em qualquer nível de convivência, podendo tornar a aquisição de uma deficiência menos dolorosa e a adaptação mais rápida, já que tem influência direta sobre a constituição da subjetividade e sobre a forma de se vivenciar a deficiência. 
Não se pode esquecer que o impacto pessoal gerado pela deficiência adquirida também é decorrente de fatores sociais e, neste sentido, uma sociedade fun- cional para todos bem como o respeito às diferenças individuais é capaz de amenizar muitas das dificuldades experimentadas neste tipo de circunstância.

\section{Referências}

Aguiar, S. Q. F. X., \& Severino, M. P. S. R. S. (2010). Impactos da deficiência adquirida nas dimensões familiar, educacional, laboral e social. In Anais do XVI Encontro de Pesquisa e Extensão. Mossoró, RN: Encope.

Alves, F. P. (2012). Deficiência física adquirida em decorrência da violência física: Representações de adolescentes e jovens. Dissertação de Mestrado, Universidade Estadual da Paraíba, Campina Grande, PA. Recuperado de http://tede.bc.uepb.edu.br/jspui/bitstream/tede/1924/1/PDF\%20-\%20Fabiana\%20Paulino\%20Alves.pdf

Bardin, L. (2011). Análise de conteúdo. São Paulo, SP: 70.

Barnes, C., Mercer, G., \& Shakespeare, T. (2005). Exploring disability. Cambridge: Polity.

Brito, D. C. S. (2009). A orientação profissional como instrumento reabilitador de pacientes portadores de doenças crônicas e deficiências adquiridas. Psicologia em Revista, 15(1), 106-119.

Castro, S. S., César, C. L. G., Carandina, L., Barros, M. B. A., Alves, M. C. G. P., \& Goldbaum, M. (2008). Deficiência visual, auditiva e física: Prevalência e fatores associados em estudo de base populacional. Cadernos de Saúde Pública, 24(8), 1773-1782. https:// doi.org/10.1590/S0102-311X2008000800006

Fechio, M. B., Pacheco, K. M. B., Kaihami, H. N., \& Alves, V. L. R. (2009). A repercussão da lesão medular na identidade do sujeito. Acta Fisiátrica, 16(1), 38-42. https://doi.org/10.5935/0104-7795.20090005

Ferreira, T. G., \& Oliver, F. C. (2010). A atenção domiciliar como estratégia para ampliação das relações de convivência de pessoas com deficiências físicas. Revista de Terapia Ocupacional da Universidade de São Paulo, 21(3), 189-197. https://doi.org/10.11606/issn.2238-6149.v21i3p189-197

Francelin, M. A. S. (2007). As implicações sociais da deficiência auditiva adquirida em adultos. Dissertação de Mestrado, Faculdade de Medicina de Botucatu, Universidade Estadual Paulista, Botucatu, SP. Recuperado de http://repositorio.unesp.br/handle/11449/98470

Francelin, M. A. S., Motti, T. F. G., \& Morita, I. (2010). As implicações sociais da deficiência auditiva adquirida em adultos. Saúde e Sociedade, 19(1), 180-192. https://doi.org/10.1590/S0104-12902010000100015

Goffman, E. (1982). Estigma: Notas sobre a manipulação da identidade deteriorada (4a ed.). Rio de Janeiro, RJ: Zahar.

Instituto Brasileiro de Geografia e Estatística - IBGE. (2012). Censo demográfico 2010: Características gerais da população, religião e pessoas com deficiência. Rio de Janeiro, RJ: o autor.

Lopes, E. M. C., \& Leite, L. P. (2013). A reorganização familiar em função da deficiência adquirida por policial militar: A visão do cônjuge. In Anais do VII Congresso Brasileiro Multidisciplinar de Educação Especial. Londrina, PR: Universidade Estadual de Londrina.

Lopes, E. M. C., \& Leite, L. P. (2015). Deficiência adquirida no trabalho em policiais militares: Significados e sentidos. Psicologia \& Sociedade, 27(3), 668-677. https://doi.org/10.1590/1807-03102015v27n3p668

Marin, C. R., \& Góes, M. C. R. (2006). A experiência de pessoas surdas em esferas de atividade do cotidiano. Cadernos Cedes, 26(69), 231-249. https:// doi.org/10.1590/S0101-32622006000200007

Martins, B. S. (2009). O “corpo-sujeito" nas representações culturais da cegueira. Fractal: Revista de Psicologia, 21(1), 5-22. https://doi.org/10.1590/S1984-02922009000100002

Martins, J. A., \& Barsaglini, R. A. (2011). Aspectos da identidade na experiência da deficiência física: Um olhar socioantropológico. Interface: Comunicação, Saúde, Educação, 15(36), 109-122. https://doi.org/10.1590/S141432832010005000043

Matsuo, M. (1999). Acidentado do trabalho: Reabilitação ou exclusão? São Paulo, SP: Fundacentro.

Murta, S. G., \& Guimarães, S. S. (2007). Enfrentamento à lesão medular traumática. Estudos de Psicologia, 12(1), 57-63. https://doi.org/10.1590/S1413-294X2007000100007 
Oliveira, R. A. (2000). Elementos psicoterapêuticos na reabilitação dos sujeitos com incapacidades físicas adquiridas. Análise Psicológica, 18(4), 437-453.

Oliveira, S. R. (2004). Os sentidos do trabalho para os dentistas filiados à Uniodonto. Dissertação de Mestrado, Escola de Administração, Universidade Federal do Rio Grande do Sul, Porto Alegre, RS. Recuperado de: http://www.lume.ufrgs.br/handle/10183/4305?locale=pt_BR

Othero, M. B., \& Ayres, J. R. C. M. (2012). Necessidades de saúde da pessoa com deficiência: a perspectiva dos sujeitos por meio de histórias de vida. Interface: Comunicação Saúde Educação, 16(40), 219-233. https://doi.org/10.1590/S1414-32832012005000010

Organização Mundial de Saúde - OMS. (2011). World report on disability. Malta: o autor.

Paiva, L. L., \& Goellner, S. V. (2008). Reinventando a vida: Um estudo qualitativo sobre os significados culturais atribuídos à reconstrução corporal de amputados mediante a protetização. Interface: Comunicação Saúde Educação, 12(26), 485-497. https:// doi.org/10.1590/S1414-32832008000300003

Patrocínio, F. F. (2010). Deficiência e autonomia: Processos de subjetivação em mulheres com deficiência adquirida. Dissertação de Mestrado, Pontifícia Universidade Católica de Minas Gerais, Belo Horizonte, MG. Recuperado de http://wwwl.pucminas.br/documentos/dissertacoes_fabiola_fernanda.pdf

Resende, M. C., \& Neri, A. L. (2009). Ajustamento psicológico e perspectiva de velhice pessoal em adultos com deficiência física. Psicologia em Estudo, 14(4), 767-776. https://doi.org/10.1590/S1413-73722009000400017

Schoeller, S. D., Bitencourt, R. N., Leopardi, M. T., Pires, D. P., \& Zanini, M. T. B. (2012). Mudanças na vida das pessoas com lesão medular adquirida. Revista Eletrônica de Enfermagem, 14(1), 95-103. https://doi.org/ 10.5216/ ree.v14il.12453

Souza, J. M., \& Carneiro, R. (2007). Universalismo e focalização na política de atenção à pessoa com deficiência. Saúde e Sociedade, 16(3), 69-84. https://doi.org/10.1590/S0104-12902007000300007

Stone-Romero, E. F., Stone, D. L., \& Lukaszewski, K. (2006). The influence of disability on role-taking in organizations. In A. M. Konrad, P. Prasad, \& J. K. Pringle (Eds.). Handbook of workplace diversity (pp. 401-430). Thousand Oaks, CA: Sage.

\section{Joelma Cristina Santos}

Mestre em Psicologia pela Universidade Federal de São João del-Rei (UFSJ), São João del-Rei - MG. Brasil.

E-mail: joelma.psicologia@yahoo.com.br

https://orcid.org/0000-0002-1016-5314

\section{Maria Nivalda de Carvalho-Freitas}

Doutora em Administração pela Universidade Federal de Minas Gerais (UFMG), Belo Horizonte - MG. Brasil.

E-mail:nivalda@ufsj.edu.br

https://orcid.org/0000-0001-7071-7179

Endereço para envio de correspondência:

Campus Dom Bosco da Universidade Federal de São João del-Rei (UFSJ). Departamento de Psicologia. Praça Dom Helvécio, 74. CEP: 36.301-160.

São João del-Rei - MG. Brasil.

Recebido 06/02/2017

Reformulado 13/03/2019

Aceito 23/04/2019

Received 02/06/2017

Reformulated $03 / 13 / 2019$

Approved 04/23/2019 
Psicologia: Ciência e Profissão 2019 v. 39, e175434, 1-16.

Recibido 06/02/2017

Reformulado 13/03/2019

Aceptado 23/04/2019

Como citar: Santos, J. C. e Carvalho-Freitas, M. N. (2019). Processos psicossociais da aquisição de uma deficiência. Psicologia: Ciência e Profissão, 39, 1-16. https://doi.org/10.1590/1982-3703003175434

How to cite: Santos, J. C. e Carvalho-Freitas, M. N. (2019).Psychosocial processes of acquiring a disability. Psicologia: Ciência e Profissão, 39, 1-16. https://doi.org/10.1590/1982-3703003175434

Cómo citar: Santos, J. C. e Carvalho-Freitas, M. N. (2019). Procesos psicosociales de la adquisición de una discapacidad. Psicologia: Ciência e Profissão, 39, 1-16. https://doi.org/10.1590/1982-3703003175434 